\title{
Esthetic and Functional Improvement of Asymmetric Lower Limb Overgrowth in a Proteus Syndrome Patient: a Combined Surgical Technique
}

\author{
Francesca Riccardi $^{1} \cdot$ Simone Catapano ${ }^{1} \cdot$ Giuseppe Cottone $^{1} \cdot$ Dino Zilio $^{1} \cdot$ Luca Vaienti $^{1}$
}

Received: 6 August 2020 / Accepted: 28 January 2021 / Published online: 9 February 2021

(C) The Author(s) 2021

\begin{abstract}
Proteus syndrome is a rare, sporadic, congenital syndrome that causes asymmetric and disproportionate overgrowth of limbs, connective tissue nevi, epidermal nevi, alteration of adipose tissue, and vascular malformations. Genetic mosaicism, such as activating mutations involving protein kinase AKT1, phosphoinositide 3 kinase (PI3-K), and phosphatase and tensin homolog (PTEN), may be important causes of Proteus syndrome. However, many patients have no evidence of mutations in these genes. Currently, the diagnosis is clinical and based on phenotypic features. This article reports a case of Proteus syndrome in a 14-yearold female patient who presented with linear epidermal nevi, viscera anomalies, and adipose tissue dysregulation. She showed an asymmetric progressive overgrowth of the right lower limb after birth bringing relevant functional and esthetic consequences. Therefore, she asked a plastic surgery consultation and a surgical treatment with a combined technique was planned. With our approach, we were able to reduce leg diameter and improve joint mobility reliably and safely with satisfying esthetic results.
\end{abstract}

Keywords Proteus syndrome $\cdot$ Lipohamartoma $\cdot$ Liposuction $\cdot$ Overgrowth $\cdot$ Genetic

\section{Introduction}

Overgrowth syndromes, such as Proteus Syndrome, represent a spectrum of disorders with global or regional overgrowth of multiple tissues such as the bone, fat, skin, and other connective tissues [1]. These syndromes are related to non-hereditary genetic mutations [2]. Proteus

Francesca Riccardi

Francesca.riccardi@unimi.it

Simone Catapano

simone.catapano1993@gmail.com

Giuseppe Cottone

gcottone.md@gmail.com

Dino Zilio

dzilio.plastic@libero.it

Luca Vaienti

luca.vaienti@unimi.it

1 Plastic Surgery Department, IRCCS Policlinico San Donato, University of Milan, Piazza Edmondo Malan, 2, 20097 San Donato Milanese, Milano, Italy syndrome is a rare sporadic disorder described in 1979 by Choen and Hayden [3] with an estimated prevalence of $<1 / 1000000$ live births [4]. In 1983, it was named "Proteus Syndrome" by Wiedemann et al., after the Greek god of the sea who was capable of assuming many forms to escape capture [5].

Primarily, it derives from sporadic activating mutation (c.49G>A, p. Glu17Lys) of an AKT gene located on chromosome $14 \mathrm{q} 32$ [6].

Proteus syndrome presents a wide variability of clinical expressions and can be hard to diagnose [5]. At birth, it can show modest manifestations or none, then develops rapidly and progressively in the early years and childhood [3], causing a distortion and overgrowth of the affected structures.

The aim of our article is to describe successful surgical technique to achieve a life-changing improvement in esthetic and functional aspects for these patients and to offer a starting point for the other plastic surgeons to treat Proteus syndromerelated soft tissue overgrowth.

On April 2019, a 14-year-old patient was admitted to our unit for the treatment of progressive postnatal overgrowth of the right lower limb (Fig. 1). She was the eldest child of healthy unrelated parents. She was born via normal vaginal 
Fig. 1. Fourteen-year-old female patient affected by Proteus syndrome with an asymmetric overgrowth of the right lower limb (a), macrodactyly of the right foot great toe and excessive adipose tissue surrounding ankle (b), and knee (c) joints

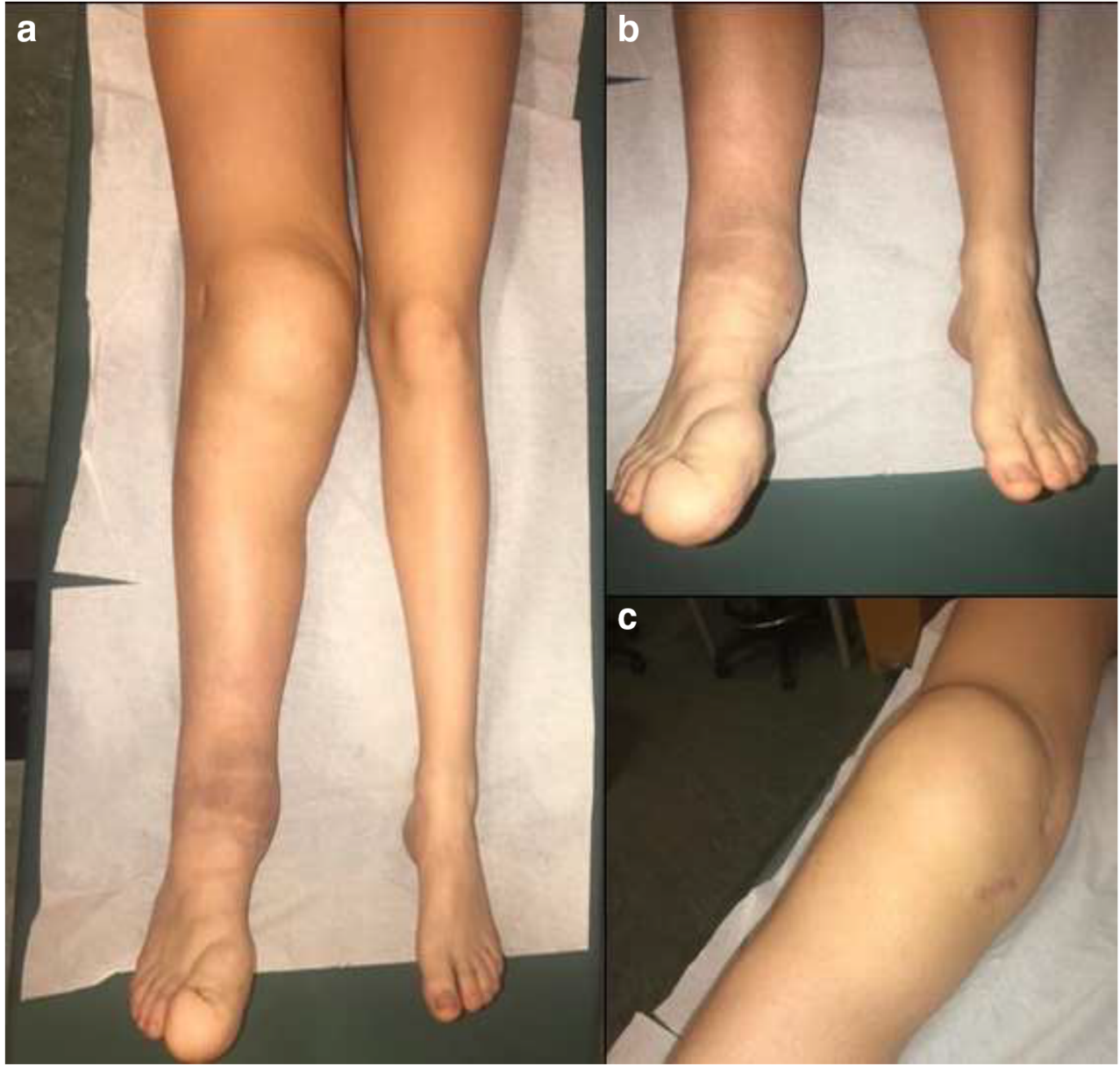

delivery after assisted fertilization and an uneventful pregnancy. She had a birth weight of $3,620 \mathrm{~g}$, a length of $51 \mathrm{~cm}$, and an APGAR score of 10/10 with a regular postnatal physical and psychomotor development.

She has two healthy younger brothers; her aunt was affected by a nephroblastoma in childhood; her mother died from a brain tumor when the patient was 12 years of age.

Three months after birth, an asymmetric growth of the lower limbs was noted, with the right leg $1.3 \mathrm{~cm}$ longer than the left. The most relevant manifestation was macrodactyly of the right foot great toe, treated with epiphysiodesis of IP joint at one year of age.

In 2014, she underwent surgery for epiphysiodesis of right knee joint. In 2015, osteotomies of the proximal and distal phalanx of the right foot great toe and removal of the eight plates from the right knee were performed.

In April 2019, aged 14, she requested a plastic surgery evaluation at our department due to concern at this time regarding both the esthetics and worsening mobility for a simultaneous and progressive hypertrophy of soft tissues surrounding the knee and the ankle joints.

In December 2019, she underwent surgery.

\section{Surgical Technique}

A comparative ultrasound exam of both legs was performed preoperatively to assess the status of soft tissues. The presence of two superficial non-pathologic adipose tissue layers, soft and separated from a well-defined fascial system, was noted. In the right limb, in a splitting of deep fascia, a third fatty layer was identified (Fig. 2). This was thicker, rich of fibrous tissue and vessel anomalies to the eco-Doppler, with all the features of a lipohamartomatous tissue.

The decision was to proceed with a combined technique: liposuction superficially and surgical removal of deep lipohamartomas [7]. The operation was performed under general anesthesia with the patient in the supine decubitus position.

The whole area of the knee was marked for liposuction in sitting position with the knee at 90 degrees of flexion to prevent the likelihood of postliposuction depression in the medial knee during flexion [8]. A tumescent solution (a dilute anesthetic solution consisting of $0.05 \%$ lidocaine and epinephrine $1: 1.000 .000$ ) [9] was prepared; $80 \mathrm{ml}$ around the knee and $50 \mathrm{ml}$ around the ankle were infiltrated using a cannula with a diameter of $3 \mathrm{~mm}$. After 15 minutes from the infiltration, 
Fig. 2. Left lower limb: two adipose tissue layer separated from a well-defined fascial system and the underlying muscle (a) right lower limb: three fatty layer with the deeper one thicker, rich of fibrous tissue and vessel anomalies (b) and the underlying muscle.

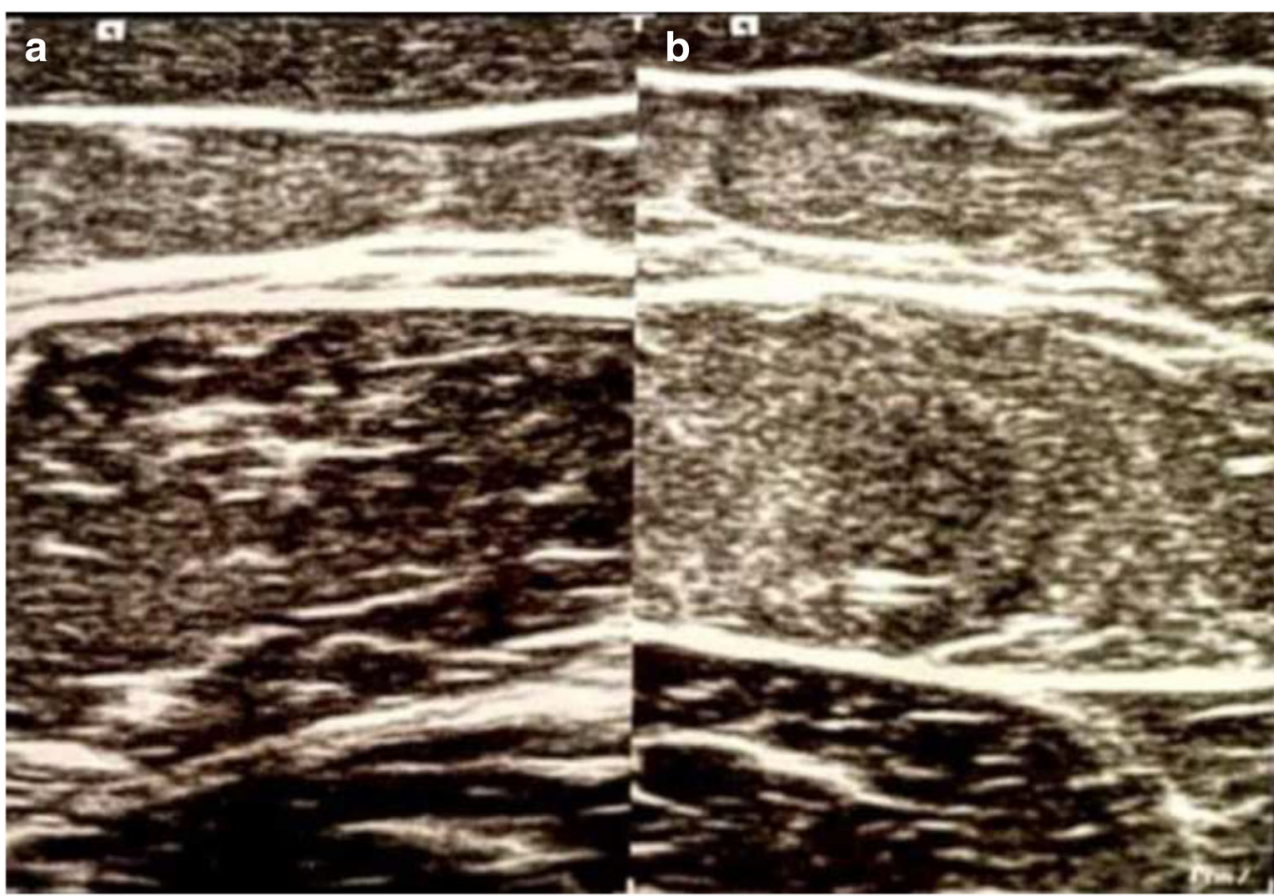

liposuction was performed; overall, $40 \mathrm{ml}$ of fat from the knee and $20 \mathrm{ml}$ from the ankle were harvested. As in classical liposuction, a fat thickness of about $2 \mathrm{~cm}$ was maintained to avoid vascular impairment and contour deformity [7].

Liposuction was performed in a very superficial layer because of the difficulty to perform this procedure in the fibrotic deeper planes and the relevant risk of fat embolism due to vessel hypertrophy in the pathological tissues. All are in line with our preoperative planning.

In postliposuction measurement, the leg diameter at the level of the knee decreased by only one centimeter (60-59 $\mathrm{cm})$ and $0.7 \mathrm{~cm}$ at the ankle region $(37-36.3 \mathrm{~cm})$.

Subsequently, it was decided to proceed with surgical removal of the subcutaneous tissue and of the excessive skin [7]. After inflation of the tourniquet $(300 \mathrm{mmHg})$, a $\mathrm{V}$ shape incision on the medial aspect of the knee was drawn. An ellipse of skin 14 by $4 \mathrm{~cm}$ in. was excised, including the residual scars of the previous orthopedic surgeries. An extended undermining of the skin and subcutaneous flap from the deeper fat tissue was performed. The excessive adipose tissue had features of that of a solid non-capsulate neoformation. The mass was removed en bloc, preserving the saphenous vein (Fig. 3). The tissue was sent for pathology.

The previous liposuction gave more mobility and elasticity to the skin flap and allowed it to slide down easily, performing a tension-free closure.

The tourniquet was released $(60 \mathrm{~min})$ and hemostasis was performed. After inserting one drain (Jackson-Pratt CH $19 \mathrm{~mm}$ ), a layered closure was performed. To reduce postoperative swelling, a lower limb bandage was applied for three weeks postoperatively and compression stockings were prescribed for a further four weeks. No serious complications occurred. At seven days followup, a seroma had formed, which had spontaneously resolved at 15 days.

Six months later, the procedure was repeated at the site of the ankle where a mass of $8 \mathrm{~cm}$ in length was removed (Fig 3 ). Attention was paid to isolate and preserve the saphenous vein to avoid chronic edema [10].

\section{Results}

Outpatient follow-up was carried out at 1 and 3 months after surgery, evaluating functional and esthetic improvement.

We measured the following:

- Flexion of the knee (78 pre-op- $95^{\circ}$ post-op) and of the ankle (5 pre-op- $15^{\circ}$ post-op)

- Leg diameter at the knee (60 pre-op-53 cm post-op) and at the ankle (37 pre-op-30 $\mathrm{cm}$ post-op)

- Foot diameter at $1 \mathrm{~cm}$ distal from the Lisfranc joint at 7 days and 3 weeks after surgery, decreased from 28 to 26 $\mathrm{cm}$, with the use of compressive bandaging

The patient, in the presence of the father, was asked to score her satisfaction with the procedure on a scale of 1 to 10 ( 1 extremely dissatisfied, 10 extremely satisfied). She scored her satisfaction as an 8 and subjectively reported a significant improvement in her walking and running ability and better fitting of clothes. 
Fig. 3. Knee region: surgical removal of prepatellar and medial lipohamartomas (a), good revascularization after deflating the tourniquet (b), and tensionfree closure due to previous liposuction of $40 \mathrm{ml}$ of superficial adipose tissue (c). Ankle region: after liposuction of $20 \mathrm{ml}$ of superficial adipose tissue, surgical removal of medial lipomhamartoma of eight $\mathrm{cm}$ in diameter (d) preserving the saphenous vein (e)
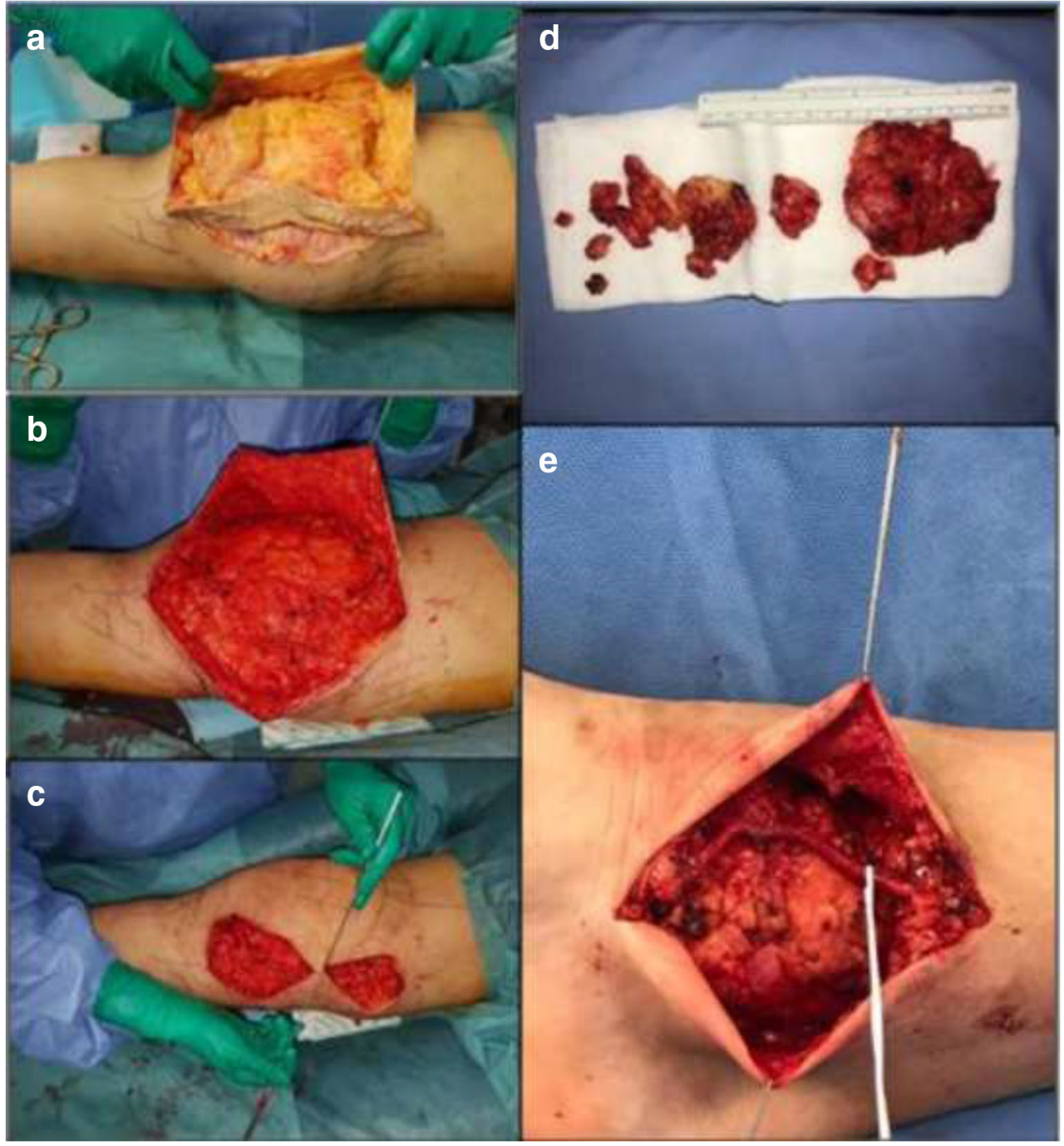

\section{Discussion}

Proteus syndrome is an extremely rare and complex disease with asymmetric postnatal overgrowth that can affect many tissues, bringing severe disfigurement and functional impairment.

The severity of this syndrome is variable; therefore, it is difficult to make differential diagnosis with other overgrowth syndromes. Given the variability of the clinical features of the Proteus syndrome, it is possible to assume that it derives from a somatic mosaicism and from certain postzygotic autosomal mutations, lethal in the no mosaic state $[2,5]$. The exact genetic cause of this uncommon disease remains unclear, although, according to recent studies, the activating mutation in the AKT1 gene is the most commonly associated. In other cases, mutations causing dysfunction of PI3K-AKT pathway or of PTEN were revealed [11]. Other investigators believe that patients with PTEN mutations presenting specific segmental overgrowth disorders (such as SOLAMEN syndrome (segmental overgrowth, lipomatosis, arteriovenous malformation, and epidermal nevus)) actually can be misdiagnosed as Proteus syndrome patients. The phenotypic overlap is due to the AKT activation deriving from PTEN loss-of-function [2].

However, many patients show negative results to all these tests [12]. Therefore, we can affirm that currently the clinical diagnosis can result from mutations in several diverse genes not yet identified.

Our patient did not present any relevant genetic mutations. From 2006 to 2010, methylation tests of H19, UPD11, and LIT1 were performed. In 2012, genes AKT, PI3K, and PTEN were analyzed on peripheral blood and on skin tissue sample. All were found to be normal. Nevertheless, the set of such alterations of the different tissues suggested a phenotypic diagnosis of Proteus syndrome, confirmed by genetic evaluation in 2012.

The clinical diagnosis of Proteus syndrome is established with the following diagnostic criteria revised by Turner et al in 2004 [13] (Table 1). 
Table 1 Diagnostic criteria of Proteus syndrome

\begin{tabular}{|c|c|}
\hline \multirow{3}{*}{$\begin{array}{l}\text { General criteria (all the } \\
\text { following criteria) }\end{array}$} & 1.Mosaic distribution of lesions \\
\hline & 2.Sporadic occurrence \\
\hline & 3.Progressive course \\
\hline \multicolumn{2}{|c|}{$\begin{array}{l}\text { Specific criteria from categories A-C ( } 1 \\
\text { from category A or } 2 \text { from category } \\
\text { B or } 3 \text { from category C) }\end{array}$} \\
\hline A. & 1.Connective tissue nevus \\
\hline \multirow[t]{3}{*}{ B. } & 1.Epidermal nevus \\
\hline & $\begin{array}{l}\text { 2.Disproportionate overgrowth (one or } \\
\text { more) } \\
\text { - Limbs Skull-hyperotsoses } \\
\text { - Vertebrae-megalospondylodysplasia } \\
\text { - Viscera }\end{array}$ \\
\hline & $\begin{array}{l}\text { 3. Specific tumors before the end of the } 2^{\text {nd }} \\
\text { decade (either one) } \\
\text { - Parotid monomorphic adenoma } \\
\text { - Bilateral ovarian cystadenomas }\end{array}$ \\
\hline \multirow[t]{3}{*}{ C. } & $\begin{array}{l}\text { 1. Dysregulated adipose tissue (either one) } \\
\text { - Lipomas } \\
\text { - Regional absence of fat }\end{array}$ \\
\hline & $\begin{array}{l}\text { 2. Vascular malformations } \\
\text { - Capillary/venous/lymphatic } \\
\text { malformation }\end{array}$ \\
\hline & $\begin{array}{l}\text { 3. Facial phenotype } \\
\text { - Dolicocephaly } \\
\text { - Long face } \\
\text { - Minor downslanting of palpebral fissures } \\
\text { and/or minor ptosis } \\
\text { - Low nasal bridge } \\
\text { - Wide or anteverted nares } \\
\text { - Open mouth at rest }\end{array}$ \\
\hline
\end{tabular}

Source: Turner et al in 2004 (13)

Our patient demonstrated all the general criteria: the disease has a mosaic distribution, as there were no other Proteus syndrome cases in her family and the manifestations had a progressive course.
As specific criteria, she presented four from category B and one from category $\mathrm{C}$.

The first and relevant alteration developed was the macrodactyly of right great toe.

She has multiple linear epidermal nevi but not cerebriform nevi of connective tissue in the palmar and plantar regions, considered almost pathognomonic [14].

She underwent to abdominal ultrasounds every three months up to the age of five, then every six months up to the age of 10; these revealed the presence of an accessory spleen.

She also presented with a development alteration of the spine, in the form of mild scoliosis identified on clinical and radiographic examinations.

In childhood, she showed a progressive subcutaneous fat hypertrophy with disorganization of the soft tissues surrounding the knee and ankle joints of the lower right limb. This caused a dysmetria of the lower limbs and asymmetry of the pelvis, responsible for intense pain and serious limitations during daily activities.

Pulmonary CT examination showed no cystic formations, and six monthly abdominal ultrasound scans revealed no genitourinary abnormalities. No cardiac complications and ocular manifestations (strabismus, retinal pigmentary anomalies, and epibulbar dermoids) were found.

Even though some capillary, venous, and lymphatic malformations are often noted in this syndrome, our patient did not show any of these anomalies both on a thorough clinical examination and on a CT angiography. The only noteworthy cutaneous finding was a dark skin area localized in the medial aspect of the right ankle: after an accurate dermatological assessment, it was attributed to a chronic hyperpigmented lichenification caused by the continuous daily rubbing between the oversized supramalleolar tissues and the shoe.

Fig. 4. a $H \& E$ 1x: lipo-vascular hamartoma predominantly composed of fatty component, sparse vessels, and focally fibrous septae. b H\&E 10x: vessels with different thick wall irregularly distributed in fatty tissue. $\mathbf{c} H \& \mathrm{E}$ 40x: well-differentiated mature adipocytes without cytological atypia

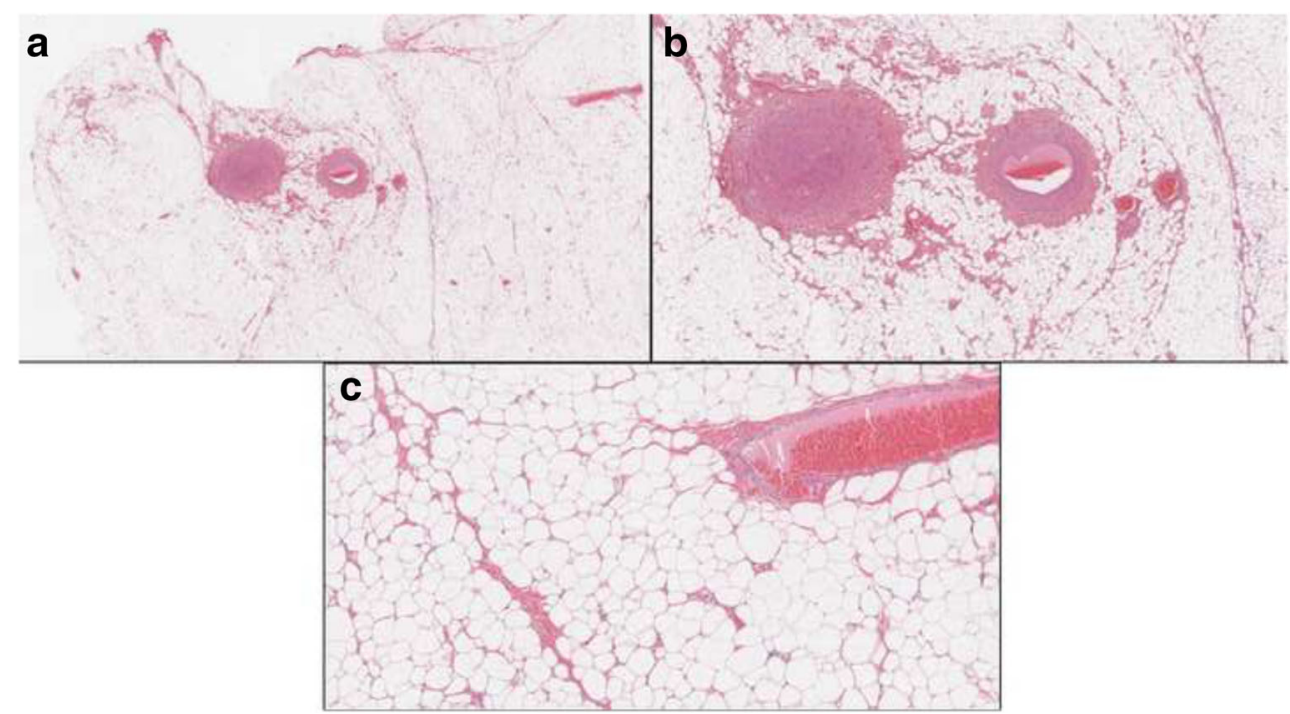


It is well known that patients with Proteus syndrome have an increased risk for deep vein thrombosis (DVT) and pulmonary embolism (PE); other researchers have argued that endothelial abnormalities, platelet dysfunction, and stasis associated with vascular malformations cause adverse effects on hemostasis [15]. However, prophylactic anticoagulation is not recommended due to the risk of life-threatening hemorrhage, especially in children, for minor trauma [16]. Only patients tested positive for DVT and PE on imaging should undergo acute anticoagulation [15]. D-dimer test was used as screening for the presence of DVT in our patient; the values below the threshold $(0.5 \mathrm{mcg} / \mathrm{dl})$ did not justify a prophylactic anticoagulation, as she was 14 years old.

Another usual characteristic of this syndrome is a dysregulation of the adipose tissue; on the one hand, lack of adipose tissue could affect some patients; no fatty tissue atrophy was revealed in our case. The young lady only showed a physiological mild breast asymmetry. On the other hand, subcutaneous as well as internal lipohamartomas of enormous size is frequently observed. Surgical intervention is indicated when they bring functional limitations to the joints and impacting esthetic effects on the patient's body, such as in our case. According to Hoey et al., the examination of our tissue samples has confirmed the histological features of pathologic adipose tissue. In most cases, they are lipohamartomas, lobules of mature adipocytes interspersed with fibrous connective tissue elements and vessels (Fig. 4). No cytological atypia was found in any case [12].

As Proteus syndrome is a rare overgrowth disorder, the literature provides scarce data on surgical approach for lower limb soft tissue dysregulation. In our hands, this combined technique is highly effective and safe.

The final results of liposuction and lipectomy were evident at approximately two months postsurgery after seroma reabsorption and reduction in postoperative swelling.

Accurate preoperative evaluation, correct surgical planning, careful intraoperative preservation of the saphenous vein, and postoperative compressive bandage allowed us to avoid severe complications. Close monitoring in the early postoperative period is necessary to detect local relapse after surgery due to the possibility of sudden adipose tissue re-overgrowth. The patient will undergo periodic six monthly checks. It was proposed to repeat the same surgical procedure at least one year after the first intervention only if relapse or dissatisfaction with surgical results. Otherwise, we wish to postpone surgical treatment when she will get skeletal maturity, treating at the same time the gigantism of great toe removing the excessive adipose tissue and covering distal phalanx with local advancement flaps.

We also recommend carrying out new, more specific analysis of the AKT gene on tissue samples from the upper dermis where the prevalence of the mutation is higher [2]. This is because the patient could benefit from pharmacological treatment with Miransertrib, an AKT inhibitor [17].

\section{Conclusion}

This case report provides a brief review of the literature and emphasizes the importance of management within a multidisciplinary team, particularly given the high rates of complications and early mortality rate of Proteus syndrome patients. The deformities caused by Proteus syndrome can carry many social problems. Our article could be a starting point for other surgeons to manage esthetic and functional problems in patients with Proteus syndrome and similar overgrowth syndromes.

Author Contribution All the authors contributed to the manuscript.

Funding Open Access funding provided by Università degli Studi di Milano within the CRUI-CARE Agreement.

Data availability All our data and material are available

Code Availability Not applicable

\section{Declarations}

Statement of Human and Animal Rights or Ethical Approval This article does not contain any studies with human participants or animals performed by any of the authors. This study was performed in line with the principles of the Declaration of Helsinki.

Informed Consent For this type of report it was required a written informed consent to the patient's father for publication.

Conflict of Interest The authors declare that they have no conflict of interest.

Open Access This article is licensed under a Creative Commons Attribution 4.0 International License, which permits use, sharing, adaptation, distribution and reproduction in any medium or format, as long as you give appropriate credit to the original author(s) and the source, provide a link to the Creative Commons licence, and indicate if changes were made. The images or other third party material in this article are included in the article's Creative Commons licence, unless indicated otherwise in a credit line to the material. If material is not included in the article's Creative Commons licence and your intended use is not permitted by statutory regulation or exceeds the permitted use, you will need to obtain permission directly from the copyright holder. To view a copy of this licence, visit http://creativecommons.org/licenses/by/4.0/.

\section{References}

1. Cohen MM (2014) Jr Proteus syndrome review: molecular, clinical, and pathologic features. Clin Genet 85:111-119. https://doi.org/10. $1111 /$ cge. 12266

2. Lindhurst MJ, Sapp JC, Teer JK, Johnston JJ, Finn EM, Peters K, Turner J, Cannons JL, Bick D, Blakemore L et al (2011) A mosaic 
activating mutation in AKT1 associated with the Proteus syndrome. N Engl J Med 365:611-619. https://doi.org/10.1056/ NEJMoa1 104017

3. Cohen MM Jr, Hayden PW (1979) A newly recognized hamartomatous syndrome. Birth Defects Orig Artic Ser 15(5B): 291-296

4. Furquim I, Honjo R, Bae R, Andrade W, Santos M, Tannuri U, Kim C (2009) Proteus syndrome: report of a case with recurrent abdominal lipomatosis. J Pediatr Surg 44:E1-E3. https://doi.org/10.1016/ j.jpedsurg.2008.12.016

5. Lublin M, Schwartzentruber DJ, Lukish J, Chester C, Biesecker LG, Newman KD (2002) Principles for the surgical management of patients with Proteus syndrome and patients with overgrowth not meeting Proteus criteria. J Pediatr Surg 37(7):1013-1020. https:// doi.org/10.1053/jpsu.2002.33832

6. De Souza RA (2012) Origins of the elephant man: mosaic somatic mutations cause Proteus syndrome. Clin Genet 81(2):123-124. https://doi.org/10.1111/j.1399-0004.2011.01807.x

7. Saldanha OR, Azevedo SF, Delboni PS, Saldanha Filho OR, Saldanha CB, Uribe LH (2010) Lipoabdominoplasty: the Saldanha technique. Clin Plast Surg 37(3):469-481. https://doi. org/10.1016/j.cps.2010.03.002

8. Okumus A (2020) Combination of lipofilling with liposuction in correction of pseudo genu varus deformity. Aesthet Surg J 40(3): NP101-NP102. https://doi.org/10.1093/asj/sjz337

9. Klein JA (1990) The tumescent technique: anesthesia and modified liposuction technique. Dermatol Clin 8(3):425-437

10. Belczak CEQ, Luiz Tyszka A, de Godoy JMP, Ramos RN, Belczak SQ, Caffaro RA (2009) Clinical complications of limb undergone harvesting of great saphenous vein for coronary artery bypass grafting using bridge technique. Rev Bras Cir Cardiovasc 24(1): 68-72. https://doi.org/10.1590/s0102-76382009000100013

11. Minglin O, Sun Z, Zhu P, Sun G, Dai Y (2017) Proteus syndrome: a case report and review of the literature. Mol Clin Oncol. https://doi. org/10.3892/mco.2017.1140

12. Hoey SE, Eastwood D, Monsell F, Kangesu L, Harper JI, Sebire NJ (2008) Histopathological features of Proteus syndrome. Clin Exp Dermatol 33:234-238. https://doi.org/10.1111/j.1365-2230.2007. 02601x

13. Turner JT, Cohen MM Jr, Biesecker LG (2004) Reassessment of the Proteus syndrome literature: application of diagnostic criteria to published cases. Am J Med Genet A 130:111-122. https://doi.org/ 10.1002/ajmg.a.30327

14. Rocha RCC, Estrella MPS, Amaral DMD, Barbosa AM, Abreu MAMM (2017) Proteus syndrome. An Bras Dermatol 92(5):717720. https://doi.org/10.1590/abd1806-4841.20174496

15. Keppler-Noreuil KM, Lozier JN, Sapp JC, Biesecker LG (2017) Characterization of Thrombosis in Patients with Proteus Syndrome. Am J Med Genet A 173(9):2359-2365. https://doi. org/10.1002/ajmg.a.38311

16. Ours CA, Biesecker LG (2020) Prophylactic anticoagulation of individuals with Proteus syndrome and COVID-19. Am J Med Genet A. https://doi.org/10.1002/ajmg.a.61861

17. Keppler-Noreuil KM, Sapp JC, Lindhurst MJ, Darling TN, BurtonAkright J, Bagheri M et al (2019) Pharmacodynamic study of Miransertib in individuals with Proteus Syndrome. Am J Hum Genet 104(3):484-491. https://doi.org/10.1016/j.ajhg.2019.01.015

Publisher's Note Springer Nature remains neutral with regard to jurisdictional claims in published maps and institutional affiliations. 